\title{
Practice of "Internet + Curriculum Ideological and Political" Teaching Mode Based on Collaborative Education
}

\author{
Haixia Li \\ Department of Information Technology and Management, Zhejiang Police Officer Vocational College, Hangzhou, China
}

\section{Email address:}

haizi321@126.com

\section{To cite this article:}

Haixia Li. Practice of "Internet + Curriculum Ideological and Political" Teaching Mode Based on Collaborative Education. Science Innovation. Vol. 9, No. 4, 2021, pp. 139-144. doi: 10.11648/j.si.20210904.14

Received: April 21, 2021; Accepted: May 19, 2021; Published: May 24, 2021

\begin{abstract}
At present, there is no systematic curriculum ideological and political teaching mode for judicial information security professional courses in higher vocational colleges, and the far-reaching influence of collaborative education mechanism and Internet technology application on curriculum ideological and political has not been fully explored. For colleges and universities, talent training must be open, which inevitably involves how to make good use of relevant resources to build a talent training mechanism. Cooperative education is to integrate all parties' education resources and energy for the purpose of talent training and use. interactive. The goal of talent training is the reform and innovation of the curriculum teaching model. "Internet +" has become a characteristic of the times. In the field of curriculum ideological and political reform, the construction of the "Internet + curriculum ideological and political" model also has a positive conceptual basis and a practical basis. And technical foundation. With the rapid development and popularization of the Internet, making full use of the advantages of Internet information to promote the further optimization and improvement of teaching is now an important way of ideological and political reform of college courses. While adhering to the concept of collaborative education, this article gives full play to the characteristics of the "Internet + " era, conducts research on the teaching mode of judicial information security professional courses and conducts online and offline mixed curriculum ideological and political teaching reforms, and has achieved good results.
\end{abstract}

Keywords: Curriculum Ideological and Political, Judicial Information Security, Internet +, Ideological and Political Reform, Collaborative Education

\section{基于协同育人的“互联网+课程思政”教学模式实践}

\section{黎海霞 \\ 信息技术与管理系,浙江警官职业学院, 杭州, 中国}

\section{邮箱}

haizi321@126.com

\begin{abstract}
摘要：目前高职院校司法信息安全专业课程还没有系统的课程思政教学模式, 还没有充分挖掘协同育人机制及互联网 技术应用对于课程思政的深远影响。对于高校来说，人才培养必须是开放性的，这就必然涉及到如何利用好相关资源 来构建人才培养机制的问题，协同育人就是以人才培养和使用为目的综合各方育人资源和能量的有效互动。而人才培 养的落脚点就是课程教学模式的改革和创新, “互联网+”已经成为一种时代特征, 在课程思政改革领域, “互联网+课程 思政”模式建构也有积极的观念基础、实践基础和技术基础。随着互联网的迅速发展和普及，充分利用互联网信息化的 优势, 促进教学进一步优化和完善, 是现在高校课程思政改革的重要途径。本文提出在秉持协同育人理念的同时, 发 挥“互联网+”时代特色, 进行司法信息安全专业课程教学模式的研究并进行线上线下混合课程思政教学改革的案例, 取 得良好成效。
\end{abstract}


关键词: 课程思政, 司法信息安全, 互联网 + , 思政改革, 协同育人

\section{1. 引言}

长期以来, 党和国家高度重视课程的育人作用 [1], 特 别是进入新时代, 发挥高校课程的育人功能被反复提及。 中共中央、国务院印发《关于加强和改进新形势下高校思 想政治工作的意见》[2]指出, “充分发掘和运用各学科蕴 含的思想政治教育资源, 健全高校课堂教学管理办法”。 习近平总书记在全国高校思想政治工作会议上[3], 强调 “要坚持把立德树人作为中心环节，把思想政治工作贯穿 教育教学全过程, 实现全程育人、全方位育人”, “要用好 课堂教学这个主渠道, 满足学生成长发展需求和期待, 其 他各门课都要守好一段渠、种好责任田, 使各类课程与思 想政治理论课同向同行，形成协同效应”。[4]总书记的重 要讲话, 既从全局和战略高度充分肯定了“协同育人”的理 念 [5], 又以鲜明的问题导向与问题意识提出了加强和改进 思想政治理论课与专业课程的重点和目标, 为高校课程的 改革发展提供了根本遵循, 指明了前进方向[7]。然而, 现 今不少高校课程思政的短板和难点仍多集中于理工类课 程方面 [8], 解决理工类专业在课程思政建设中的实际操作 问题显得迫在眉睫 $[10]$ 。

课程思政作为解决高等院校培育什么人以及如何培 育人这一根本问题的新型范式其主要目标在于落实互联 网和课程教育的充分结合, 继而提高价值引导与意识形态 领域的教学成效, 使课程思政功能更为显著。因此, 互联 网+课程思政教育模式不论是知识讲授, 还是价值引导, 均是学生个体认知领域理念重构的具体过程。“互联网+ 课程思政”教学模式的意义重大, 一是有利于激发学生学 习兴趣, 提升课程思政作用; 二是有利于重构优化课程内 容, 催生教学方法变革; 三是有利于引导转化思政价值, 激发学生学以致用; 四是有利于传道受业解惑结合, 实现 潜移默化教育。

本文以司法信息安全专业课程为例, 从理工专业的 课程属性出发, 结合“双高计划”专业课线上线下混合教 学的模式 [16], 给出了基于协同育人的“互联网+课程思 政”的教学模式案例。教师认真负责, 主导教学过程, 结合课堂、课堂教学、课外实践、网络平台协同育人, 使得学生达到知识积累、能力与素质共同提升。通过探 索基于协同育人的“互联网+课程思政”教学模式，包括 协同育人的各方主体协作模式, 互联网+思政的教学内 容, 教学手段及教学评价方式[26]。在高职院校计算机 专业课程教育教学过程中利用互联网+技术及线上线下 教学渗透思想政治教育, 在课堂教学的主渠道之中落实 教书育人内涵, 有机结合知识传授与价值引领, 在价值 传播中既注重凝聚知识底蕴, 又强调价值引领。协同育 人为帆, “互联网+课程思政”教育为船, 两者有机结合, 全过程、全方位、全员培养具备较高综合职业素养的高 职院校毕业生。

\section{2. 教学设计方案}

\section{1. 教学理念}

以培养学生的职业能力与综合素质为导向, 在“场景 导入、技能发展、课程思政”的教学设计思路指导下 [15], 实现课、岗、赛“三融合”，同时践行“全过程、全方位、 全员”的“三全育人”模式[13], 并结合“情境教育、劳动教 育、课程思政教育”于一体的“三教培养”[11], 在理实一体 教学、反复强化训练中实现“三融、三全、三教”的教学理 念[6], 如图1所示。

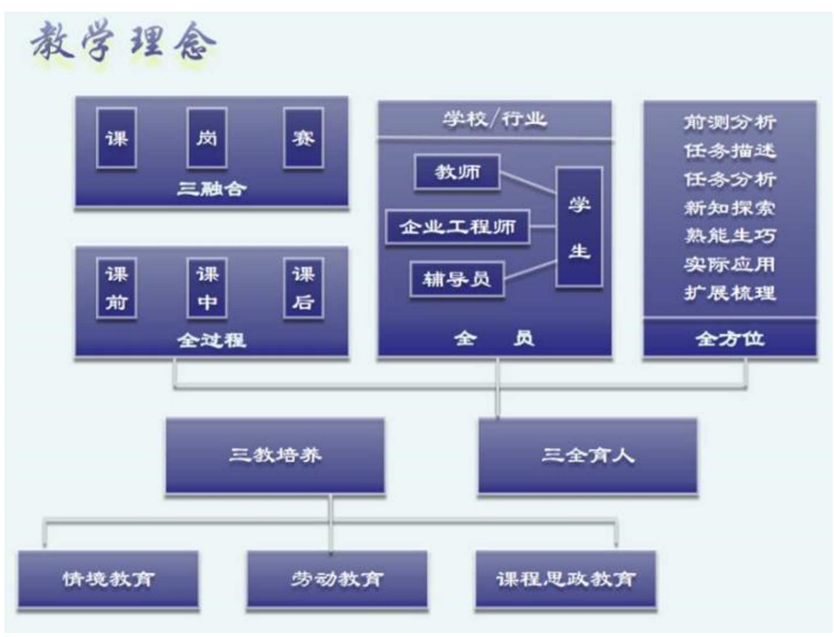

图1《信息安全管理实务》教学理念。

\section{2. 教学目标}

本案例的授课对象为信息安全与管理/司法信息安全 专业第五学期学生, 摸底测试及问卷调查结果显示有信息 安全技术的基础, 学习积极性高, 热衷实践操作, 但安全 管理理念和安全意识不高, 技能掌握不牢固, 职业素养等 有待进一步培养。在进行学情分析后确定教学目标, 教学 目标从三个维度进行分析和研究, 分别是知识目标、能力 目标以及素质目标[17]。

知识目标: 掌握信息安全风险评估、网络安全等级保 护流程与方法等课程知识点; 掌握岗位需求及信息安全竞 赛要求的知识及内容, 达到“三融”知识目标。

能力目标: 信息安全风险评估能力; 企业信息安全策 略制定能力; 网络安全等级保护测评能力等职业能力。

素质目标: 具有质量意识、团队意识、安全意识、劳 动意识、工匠精神。

\section{3. 教学策略}

结合“三融、三全、三教”的教学理念及学情分析, 实 施“五融合”混合教学策略, 即不同练习内容相融合、多种 教学形式相融合、多样化练习形式融合、多种互动途径相 
融合、多维评价方式相融合, 教学策略如图2所示。并利 用“互联网+课程思政”教学模式 [18], 线上线下混合教学方 式的过程通过教师和学生的配合来完成。

教学过程实施“教师-学生”二维度七步骤[19], 即: 通 过 (1) 前测分析：教师“线上布置任务线下针对性教”;

（2）任务描述：学生“线上预习线下针对性学”;（3）任 务分析：教师“线下分析线上展示”[14];（4）新知探索: “教师线下讲解线上测试” (5) 孰能生巧: 学生“线下练习 线上提问”（6）实际应用：学生“线上课后练线下讨论”;

(7) 拓展梳理: 教师“线上查漏线下补缺”七个步骤两个 维度开展教学。

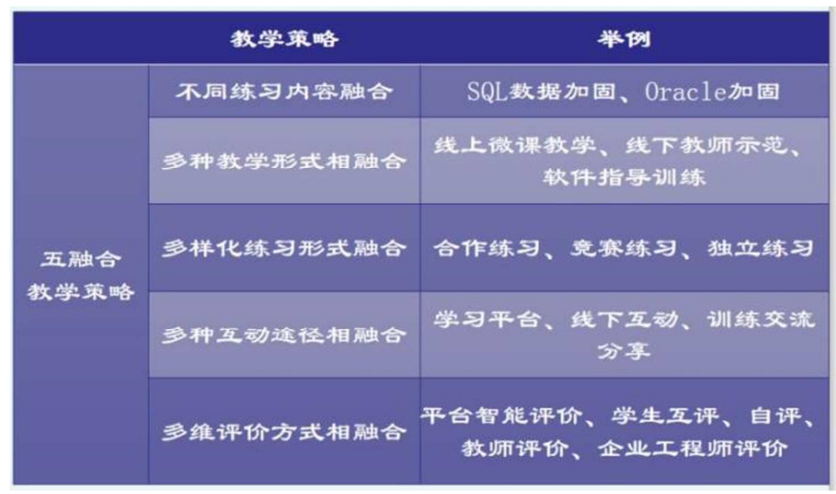

图2 《信息安全管理实务》教学策略。

教学资源包括配套校企合编的省十一五重点教材《信 息安全管理实务》（已立项省十三五新形态教材），利用 职教云平台上电子课件、练习题、微课、案例库等教学资 源, 在信息安全综合实训室进行实训, 教学方法包括小组 讨论法、实训演示法等。

\section{4. 考核评价}

本案例采取多种考核方式, 注重实践操作技能和应用 能力的考核。课程考核总分 100 分, 其中线上考核占 $40 \%$, 实践技能考核占 $30 \%$, 期末考核 $20 \%$, 教师评价及学生互 评10\%四大部分。[21]

\section{3. 课程主要内容及具体实施情况}

\section{1. 课程情境化教学内容}

本案例课程以学习情境与所需掌握的技能一一对应 理念为导向设计学习情境如下:

学习情境1: “信息安全风险评估”是建立信息安全管 理体系的基础, 也是风险管理的前沿领域;

学习情境2: “信息安全策略制定”结合环境特色及企 业情况为组织制定信息安全策略;

学习情境3: “信息安全教育”, 信息安全策略制定好 以后需要通教育来推行;

学习情境4: “网络安全等级保护”是网络安全法规定、 当前国家正在进行的一项确保信息系统安全的重要工作;

以学习情境作为工作任务, 以任务为驱动, 为了反映 教学内容的前沿性和时代性共分为了 8 个模块, 分别为课
程导学、监狱信息安全概述、信息安全风险评估、信息安 全管理制度制定、信息安全教育、网络安全等级保护、信 息安全法律法规及拓展学习资料。

“互联网+课程思政”线上学习资源在职教云上共导入 了课程各种类型学习资源共 604 个, 包括 130 个视频课件、 393 个非视频课件, 70 个文本类文件, 264道习题, 微课61 个, 其中包括思政教学案例 300 多个。

\section{2. 教学组织形式}

课程采用“五融合”教学策略展开教学, 教学组织分为 两个阶段, 第一阶段为假期纯线上教学阶段, 以学生自学 为主, 教学方法主要是视频讲解法、操作录屏示范法、测 试法; 第二阶段为学校开学后线上线下混合教学阶段, 主 要通过课堂组织, 利用职教云平台, 并在信安综合实训室 进行实训, 教学方法包括小组讨论法、案例教学法、实验 演示法等。

\section{3. “互联网+课程思政”教学安排}

教学过程分为前测分析、任务描述、任务分析、新知 探索、孰能生巧、实际应用及拓展梳理7个步骤完成。每 一个过程分为线上和线下两部分。如前测分析主要是教师 提前在职教云上导入课程的教学资源和题库, 并布置相应 任务, 学生根据个人知识掌握情况利用职教云课程资源进 行预习并完成相应任务, 线下针对性学; 教师可以精准进 行学情分析, 线下针对性教。每个过程的线上线下教与学 过程如图3所示。



图3 线上线下混合方式。

\section{4. 学生混合式学习情况}

课程中共布置了 21 次, 完成在线批改作业 145 人次, 8 次签到, 2次问卷调查, 6次头脑风暴, 4次讨论, 24次课 堂提问, 2 次测验, 取得了较好的教学效果。线上教、学、 做、查一体化教学模式取得了较好的成效, 学生网络安全 测评能力有了较大地提高, 网络安全意识及自主学习能力 
明显增强, 同时也体现出课程有一定难度, 需要跳一跳才 能够得着, 学生探究式学习能力还需进一步培养。

\section{4. 课程考核情况}

\section{1. 课程“互联网+课程思政”考核与评价方式方法}

本课程采取多种考核方式与考核手段, 具体为:

课程考核总分 100 分，其中线上考核占 $40 \%$ ，实践技 能考核占 $30 \%$, 期末考核 $20 \%$, 教师评价及学生互评 $10 \%$ 四大部分, 如图4所示。

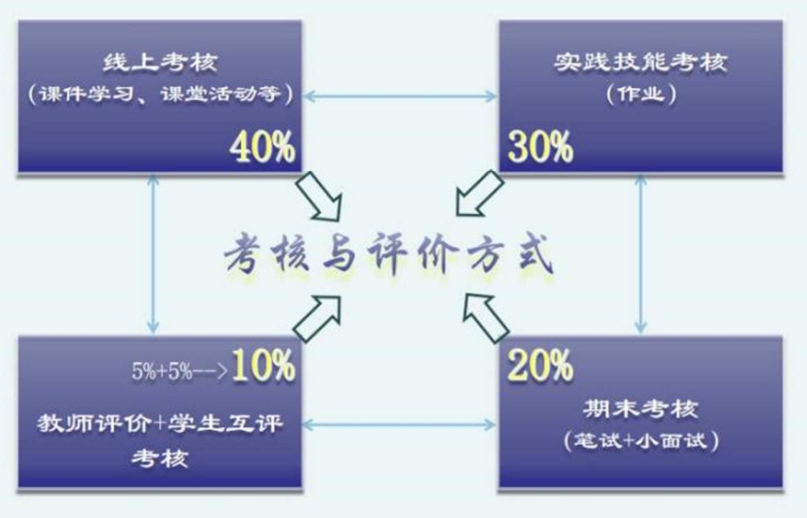

图4 考核与评价方式。

(1)线上考核 ( $40 \%)$, 包括4个考核项目, 如图5所示。

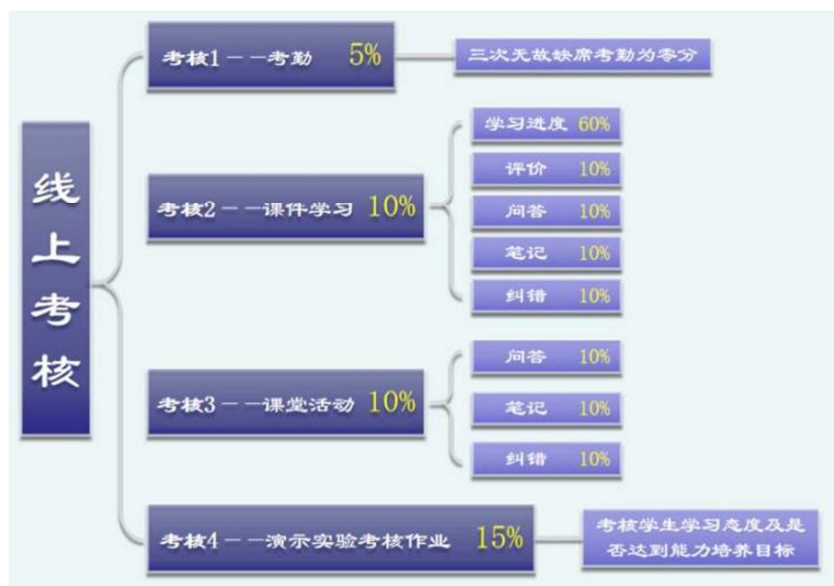

图5 线上考核评分方式。

考核项目 1: 考勤考核 $(5 \%)$ 三次无故缺席考勤为零分。 考核项目 2: 课件学习 $(10 \%)$, 其中学习进度 $60 \%$, 评 价 $10 \%$, 问答 $10 \%$, 笔记 $10 \%$, 纠错 $10 \%$ 。

考核项目3: 课堂活动 $(10 \%)$, 其中参与 $20 \%$, 课堂表 现分 $20 \%$, 测验平均分 $60 \%$ 。

考核项目 4 : 演示实验考核 $(15 \%)$ 考核学生学习态度及 是否达到能力培养目标。

(2) 实践技能考核 $(30 \%)$

考核项目 5 : 实践项目技能考核作业, 查看学生是否 具备解决复杂问题的综合能力和高级思维。

(3) 期末考核 $(20 \%)$
考核项目 6: 笔试 $(10 \%)$ 检测学生是否达到知识目标。 考核项目 7: 小面试(10\%) 检测学生是否具备职业能 力及素养。

（4）教师评价及学生互评考核（10\%）

考核项目 8:教师评价 $(5 \%)+$ 学生互评 $(5 \%)$ 根据学生 综合表现给出教师评分互评分。

\section{2. 近两学期学生成绩分析}

课件学习成绩只有两名同学在 60 分以下, 其余均为 60 分; 课堂活动最低分 33.3 分, 最高分 83.1 分; 作业最低 4.88 分, 最高17.56分; 学习时长最低12时7分48秒, 最多7704 时 21 分 10 秒; 按照上述线上成绩比例计算有一名学生未超 过60分, 其余为60 61分, 说明线上参与度良好。

\section{5. 课程教学效果及课程特色}

\section{1. 学生学习效果分析}

5.1.1. 通过课、岗、证内容互相融合, “三融”效果显著 通过课程知识的掌握更符合岗位需求, 对口企业对本 专业的学生需求量为 20 人/年, 去等保测评公司的学生均 取得网络安全等级保护测评师证书; 曾获省 CTF竞赛二等 奖, 三等奖，体现课程“课、岗、证”实施效果。

\subsection{2. 通过全员、全过程、全过程教学模式, “三全”效果 显著}

通过学校/行业“全员”参与, 课前、课中、课后“全过 程”教学模式, 二维七步“全方位”实施, 学生能够进行信 息安全风险评估、等级保护测评及安全加固等操作。

\subsection{3. 通过情境教育、劳动教育、课程思政教育, “三教” 效果显著}

通过情境教育学生对岗位更熟悉, 劳动教育使学生具 有劳动意识和工匠精神。同时网络安全意识、质量意识、 分析问题解决问题等职业能力得到了较大提升。

\section{2. 学生和教学督导评价}

学习完课程各模块后, 目标岗位更加准确, 职业规划 更加清晰, 明确要考取相应证书并表示会积极参加信息安 全相关竞赛, 以赛促学。

教学督导对教学理念及模式表示肯定, 鼓励在“双高 计划”背景下发挥价值链聚同效应, 寻求产教利益融合, 形成产业链-人才链-教育链的莫比乌斯价值环。

\section{6. 课程进一步优化提升及推广计划}

\section{1. 优化提升}

\subsection{1. 进一步深化“三融、三全、三教”的教学理念}

针对“信息安全与管理专业”职业能力及未来岗位需 求, 优化课、岗、赛“三融合”, 健全“全过程、全方位、 
全员”的“三全育人”模式，深化“情境教育、劳动教育、课 程思政教育”于一体的“三教培养”。

\subsection{2. 进一步细化“二维七步”的教学步骤}

从广度和深度两方面来优化, 一是扩展教师、企业工 程师、辅导员和学生多维度教学, 二是深挖前测分析、任 务描述等步骤全方位展开教学。

\subsection{3. 进一步优化“校企一体、形式多元”的教学资源}

校企合作协同更新教学项目, 开发和设计更加符合学 生认知规律的教学资源, 如新形态教材、多媒体教学资料 等[12]。

\section{2. 推广计划}

\subsection{1. 以“竞赛”为平台推培养模式}

通过教师加入竞赛组委会、担任竞赛裁判、学生参 加信息安全相关的技能竞赛等方式, 与参赛院校师生、 企业沟通交流，优化推广“课、岗、赛”融通的人才培养 模式。

\subsection{2. 以“产教”为契机推教学资源}

通过深化校企合作来优化教学资源和内容, 同时将建 立好的课程推广给企业作为新入职员工培训资源。

\subsection{3. 以“教研”为抓手推教学方法}

进一步探索教学方法与教学手段, 总结教学方法及 经验, 通过案例申报及论文发表等方式推广教学模式及 方法。

\section{7. 结论}

高校课程思政协同创新是一项巨大的工程，必须以 “立德树人”为根本任务和核心目标, 以课程为出发点, 各门课程、各类课堂、所有教师坚持马克思主义理论为 指导下的育人导向, 开展思政资源渗透 [22]。目前, 高校 在育人工作的网络化、现代化探索当中, 网络对于以往 教育模式仅发挥着补充及辅助作用, 课程思政教育的第 一课堂将传统教育为主、线上课程教育为辅的观念尚未 在本质上获得改变。另一方面, 要突破互联网仅为第一 课堂教育过程服务的守旧思想。互联网并非仅是第一课 堂教育的有效补充, 是高校第一课堂教育工作不可被割 裂的重要构成部分。“互联网+课程思政”是解决高校“培 养什么人，如何培养人，以及为谁培养人”这个根本性问 题的新范式[20]。其目标是实现互联网与课程教学深度融 合, 从而提升价值引领和意识形态教育效果, 让课程的 “思政”作用更加明显。

\section{致谢}

本文为浙江省2021年度高等学校课程思政教学研究 项目《基于协同育人的“互联网+课程思政”教学模式在高
职院校计算机类专业课程中的应用与研究》的阶段性成果 之一。

\section{参考文献}

[1] 间长斌,郭院成. 推进专业思政与课程思政耦合育人:认识、 策略与着力点[J].中国大学教学,2020(10):35-41.

[2] 刘玉洁,郑丽,熊力,石瑛,邹爱玲.“课程思政”融入大学物理实 验教学的探索与思考[J].物理通报,2020(10):2-5.

[3] 李春萌,马翠风.三全育人格局下课程思政建设的实践探索 —以广西水利电力职业技术学院为例 [J].中国职业技术 教育,2020(26):55-58.

[4] 高迎爽,李楠.抗疫时期推进课程思政的理念与实践[J].中国 大学教学,2020(08):59-64.

[5] 吴和喜“互联网+课程思政”模式建构的理论探究 [J].吉林省 教育学院学报,2020,36(06):86-89.

[6] 戚静. 高校课程思政协同创新研究[D].上海师范大学, 2020 .

[7] 夏嵩,王艺霖,肖平,富海鹰.土木工程专业教育中工程伦理因 素的融入——课程思政”的新形式 [J]. 高等工程教育研 究,2020(01):172-176.

[8] 朱征军,李赛强.基于一致性原则创新课程思政教学设计 [J]. 中国大学教学,2019(12):24-28.

[9] 刘隽,范国睿.高校“课程思政”改革背景下师生互动对于学 生自我收获感与满意度的影响机理——基于结构方程模型 的实证分析 [J].现代教育管理,2019(05):117-123.

[10] 孙志伟. 理工类专业课程开展课程思政建设的关键问题与 解决路径[J].思想政治课研究,2019(01):93-97.

[11] 郭燕锋,姜峰,陈晓阳.创新协同育人机制,提升人才培养质量 — 以华南农业大学为例 [J]. 科技管理研 究,2018,38(22):105-110.

[12] 高宁,张梦.对“课程思政”建设若干理论问题的“课程论”分 析[J].中国大学教学,2018(10):59-63.

[13] 冯亚青,陈立功,张宝,闵喜龙,徐加良.化工类专业课程思政 与教学改革探索——以“精细有机合成化学及工艺学”为例 [J].中国大学教学,2018(09):48-51.

[14] 郑毅龙.“互联网+思政课程”模式建构的理论研究 [J].中国战 略新兴产业,2018(40):234.

[15] 朱明,王茜,燕彩蓉,潘乔,王绍宇. 基于思维创新的计算机网 络课程思政教学改革研究 $[\mathrm{C}]$. 上海来溪会务服务有限公 司.Proceedings of 2018 3rd International Conference on Education and Innovation（EDUINNOV2018）.上海来溪会 务服务有限公司:上海来溪会务服务有限公司,2018:84-89.

[16] 余江涛,王文起,徐晏清.专业教师实践“课程思政”的逻辑及 其要领—以理工科课程为例 $[\mathrm{J}]$. 学校党建与思想教 育,2018(01):64-66. 
[17] 王光彦.充分发挥高校各门课程思想政治教育功能[J].中国 大学教学,2017(10):4-7.

[18] 高燕.课程思政建设的关键问题与解决路径 [J].中国高等教 育, 2017(Z3):11-14.

[19] 刘淑慧. “互联网+课程思政”模式建构的理论研究[J].中国高 等教育,2017(Z3):15-17.
[20] 陈爽.基于协同育人视角的中国特色现代学徒制探析 [J].中 国职业技术教育,2015(30):76-79.

[21] 王丹中,赵佩华.产教融合视阈下高职院校协同育人机制探 索[J].中国高等教育,2014(21):47-49.

[22] 徐平利. 试论高职教育“协同育人”的价值理念 [J].职教论 坛,2013(01):21-23. 